\title{
Microestrutura e Características Mecânicas da Zona Fundida de um Aço Naval Soldado ao Arco Submerso com Aporte Térmico Muito Elevado ${ }^{a}$
}

\author{
Luiz Henrique Soares Barbosa ${ }^{1}$, Paulo José Modenesi ${ }^{1}$, Leonardo Barbosa Godefroid², Tadeu Messias Donizete Borba ${ }^{3}$ \\ 1 Universidade Federal de Minas Gerais - UFMG, Departamento de Engenharia Metalúrgica e de Materiais, Belo Horizonte, \\ MG, Brasil. \\ 2 Universidade Federal de Ouro Preto - UFOP, Departamento de Engenharia Metalúrgica e de Materiais, Ouro Preto, MG, Brasil. \\ 3 Centro de Pesquisa \& Desenvolvimento Usiminas - Usiminas, Ipatinga, MG, Brasil.
}

Recebido: 26 Mar., 2018

Aceito: 27 Maio, 2018

E-mails: Ihsbop@yahoo.com.br (LHSB), modenesi@demet.ufmg.br (PJM), leonardo@demet.em.ufop.br (LBG), tadeu.borba@usiminas.com (TMDB)
Trabalho apresentado no XLIII CONSOLDA Congresso Nacional de Soldagem, 06 a 09 de novembro de 2017 Joinville - SC, Brasil.

Este é um artigo publicado em acesso aberto (Open Access) sob a licença Creative Commons Attribution Non-Commercial, que permite uso, distribuição e reproduçăo em qualquer meio, sem restriçōes desde que sem fins comerciais e que 0 trabalho original seja corretamente citado.
Resumo: A soldagem de alto aporte térmico é uma alternativa que tem sido empregada na indústria naval e de petróleo para reduzir o número de passes de soldagem em estruturas espessas por meio do aumento da taxa de deposição. Isso tem levado desenvolvimento de aços e de consumíveis que permitem a obtenção de juntas com aceitável nível de tenacidade na zona termicamente afetada, mesmo com aportes térmicos muito elevados. Contudo, ainda não são muito claras as consequências do ponto de vista metalúrgico que este procedimento pode acarretar na zona fundida. O presente trabalho avalia a influência de aportes térmicos de até $17,1 \mathrm{~kJ} / \mathrm{mm}$ na microestrutura e características mecânicas da zona fundida obtida na soldagem de um aço naval TMCP EH36 feita em único passe com o processo ao arco submerso multi-eletrodos e com adição de arame frio. A microestrutura foi comparada com a de soldas realizadas com energia menor e mapas de dureza foram produzidos e comparados, avaliando-se também a eficiência dos consumíveis geralmente aplicados para a soldagem e alto aporte. Foi observado que o teor de molibdênio na solda contribui de forma direta para a manutenção das propriedades mecânicas da zona fundida na soldagem de alto aporte térmico.

Palavras-chave: Aço TMCP EH36; Arco submerso; Arame frio; Metalurgia da soldagem; Alto aporte térmico.

\section{Microstructure and Mechanical Characteristics of the Welding Zone of a Shipbuilding Steel Welded in Submerged Arc Welding with Very High Heat Input}

\begin{abstract}
High heat input welding is an alternative that has been employed to reduce the number of welding passes in thick structures with increasing deposition rate. This has led to the development of steels and consumables that allow to obtain joints with acceptable level of toughness in the Heat Affected Zone, even with very high heat inputs. However, the metallurgical consequences, which this procedure can cause in the welding zone, are not very clear yet. This research evaluates the heat input effect up to $17.1 \mathrm{~kJ} / \mathrm{mm}$ on the microstructure and mechanical properties of the welding zone obtained in the welding of a TMCP EH36 shipbuilding steel in single pass with the submerged arc multi-electrodes with addition of cold wire. The microstructure was compared with that of welds performed with lower heat input and hardness maps were produced and compared, also evaluating the efficiency of consumables generally applied for welding and high input. It was observed that the molybdenum content in the weld acts directly to the maintenance of the mechanical properties of the welding zone in the high heat input welding.
\end{abstract}

Key-words: TMCP EH36 steel; Submerged arc welding; Integrated cold electrode; Welding metallurgy; High heat input.

\section{Introdução}

A soldagem multipasses, comumente aplicada em chapas de grande espessura voltadas principalmente para a indústria naval, promove a formação de uma microestrutura complexa na zona fundida, devido às condições de solidificação impostas e ao reaquecimento promovido pelos passes subsequentes. Como consequência, tem-se a formação de uma fina população de inclusões e o aparecimento de constituintes que podem afetar 
Microestrutura e Características Mecânicas da Zona Fundida de um Aço Naval Soldado ao Arco Submerso com Aporte Térmico Muito Elevado

negativamente a tenacidade nessa região [1]. Mas, de maneira geral, um maior número de passes favorece o desenvolvimento de soldas com melhor comportamento mecânico, porém reduz a produtividade do processo.

A redução do número de passes, geralmente é proporcionada pelo aumento a taxa de deposição, em paralelo com um aumento do aporte térmico por passe, sendo possível, no limite, chegar a um patamar de soldagem de único passe para aplicação em estruturas de elevada espessura. Para esta aplicação, a soldagem ao arco submerso já é largamente empregada por possuir inúmeras vantagens já conhecidas industrialmente, dentre elas, a possibilidade de uma fácil adaptação para realizar a soldagem com vários arames e fontes operando simultaneamente [2]. Formas eficientes de aumento da taxa de deposição, com redução do número de passes, tem sido estudadas há alguns anos, destacando-se, principalmente a soldagem com mais de um arame e com adição de pó metálico [3-5]. Um método alternativo [6] também usado, que tem chamado a atenção mais recentemente, para aumentar a taxa de deposição é a adição de arame não energizado (arame frio) [7,8]. Este método, que se aperfeiçoa ao longo dos anos, vem ganhando destaque com desenvolvimentos recentes e apresenta-se com um grande potencial de ganho de produtividade sem aumentar ainda mais a entrada de calor [9].

O uso de aportes térmicos muito elevados submete a região da solda a ciclos térmicos de longa duração com baixas velocidades de resfriamento e elevados tempos de permanência em temperaturas acima de $1200{ }^{\circ} \mathrm{C}$ formando uma poça de fusão de grandes dimensões e volume de metal líquido. As baixas velocidades de resfriamento e longos tempos de permanência a alta temperatura favorecem a formação de estruturas de solidificação com grande espaçamento, o crescimento de grão austenítico e a consequente formação de estruturas grossas formadas predominantemente por ferrita de contorno de grão e ferrita intragranular, bem como com a redução da fração volumétrica de ferrita acicular [5,10]. A microestrutura resultante contribui diretamente para degradar a tenacidade à fratura da zona fundida e espera-se que essa região apresente tendência à fratura dúctil e menor dureza [11,12] tornando-a menos resistente que a ZTA e o metal base.

Neste contexto, uma preocupação relevante na soldagem de alto aporte é escolha do metal base e dos consumíveis a serem utilizados. Como resultado das condições operacionais usadas, a zona termicamente afetada tende a ser mais extensa do que na soldagem multipasses [13]. Estudos realizados nas últimas décadas [14-16], particularmente para aplicações navais, mostram a eficiência dos aços TMCP (Thermo-Mecanical Control Processing) para aplicação nestas condições e estes têm sido cada vez mais utilizados para este fim.

A soldagem ao arco submerso com elevados aportes térmicos (superiores a cerca de $10 \mathrm{~kJ} / \mathrm{mm}$ ) e único passe para estruturas de responsabilidade não é usual no Brasil e é utilizada atualmente em poucos países, sobretudo os asiáticos [17]. Além disto, embora o desenvolvimento de aços para aplicações neste tipo de soldagem tenha evoluído muito nas últimas décadas, pouco é divulgado sobre o desenvolvimento de consumíveis para este tipo de aplicação. O presente trabalho apresenta, neste contexto, uma caracterização microestrutural e mecânica do metal de solda produzido com aporte térmico de 2,8, 6,9, 10,7 e 17,1 kJ/mm, com o uso de arame frio. Trata-se da parte inicial de um estudo maior que pretende avaliar o comportamento em fadiga dessas juntas soldadas. Portanto, a caracterização mecânica realizada aqui contou apenas com medidas básicas de dureza e tração, não envolvendo a tenacidade. Foi feita uma comparação microestrutural para quatro valores de aporte térmico mantendo-se os mesmos consumíveis. Além disso, para o maior valor de aporte $(17,1 \mathrm{~kJ} / \mathrm{mm})$ foi repetido o processo, adicionando-se um arame ligado, visando uma comparação do comportamento desses consumíveis, tipicamente usados para soldagem de alto aporte.

\section{Materiais e Métodos}

O material objeto deste estudo foi obtido a partir de juntas de $25 \mathrm{~mm}$ de espessura soldadas pelo processo SAW ICE ${ }^{T M}$ em único passe. O metal base foi um aço TMCP EH36, fabricado por laminação controlada, seguida de resfriamento acelerado fornecido por um fabricante nacional e a sua composição química é mostrada na Tabela 1 , estando dentro dos padrões definidos pela Norma ASTM A131M-14 [18].

Tabela 1. Composição química do metal base (\%pp).

\begin{tabular}{cccccccccc}
\hline $\mathbf{C}$ & $\mathbf{M n}$ & $\mathbf{S i}$ & $\mathbf{P}$ & $\mathbf{S}$ & $\mathbf{C u}$ & $\mathbf{C r}+\mathbf{N i}+\mathbf{M o}$ & $\mathbf{N b}+\mathbf{V}+\mathbf{T i}$ & $\mathbf{C}_{\text {eq }}{ }^{*}$ & $\mathbf{P}_{\mathrm{cm}}{ }^{* *}$ \\
0,102 & 1,377 & 0,229 & 0,019 & 0,004 & -- & 0,017 & 0,012 & 0,336 & 0,180 \\
\hline${ }^{*} C_{\text {eq. }}=C+M n / 6+(\mathrm{Ni}+\mathrm{Cu}) / 15+(\mathrm{Cr}+\mathrm{Mo}+\mathrm{V}) / 5 ;{ }^{* *} \mathrm{P}_{\mathrm{cm}}=\mathrm{C}+\mathrm{Si} / 30+(\mathrm{Mn}+\mathrm{Cu}+\mathrm{Cr}) / 20+\mathrm{Ni} / 60+\mathrm{Mo} / 15+\mathrm{V} / 10+5 \mathrm{~B}$. \\
\hline
\end{tabular}


O material foi cortado em cupons de $150 \mathrm{~mm}$ de largura e $600 \mathrm{~mm}$ de comprimento e juntas para a soldagem com aporte térmico mais elevado foram preparadas de acordo com o desenho mostrado na Figura 1. Utilizou-se como metal de adição o arame AWS EM12K (ESAB OK Autrod 12.22) para todas as energias empregadas. Já o AWS EA2 (ESAB OK Autrod 12.24) foi usado apenas na tocha CC+ para a condição de 17,1 kJ/mm. Em todas as soldas utilizou-se o fluxo aglomerado básico (OK Flux 10.71). A Tabela 2 apresenta as composições químicas e propriedades mecânicas típicas do metal depositado pelos conjuntos de arame e fluxo de acordo com o seu fabricante [19].

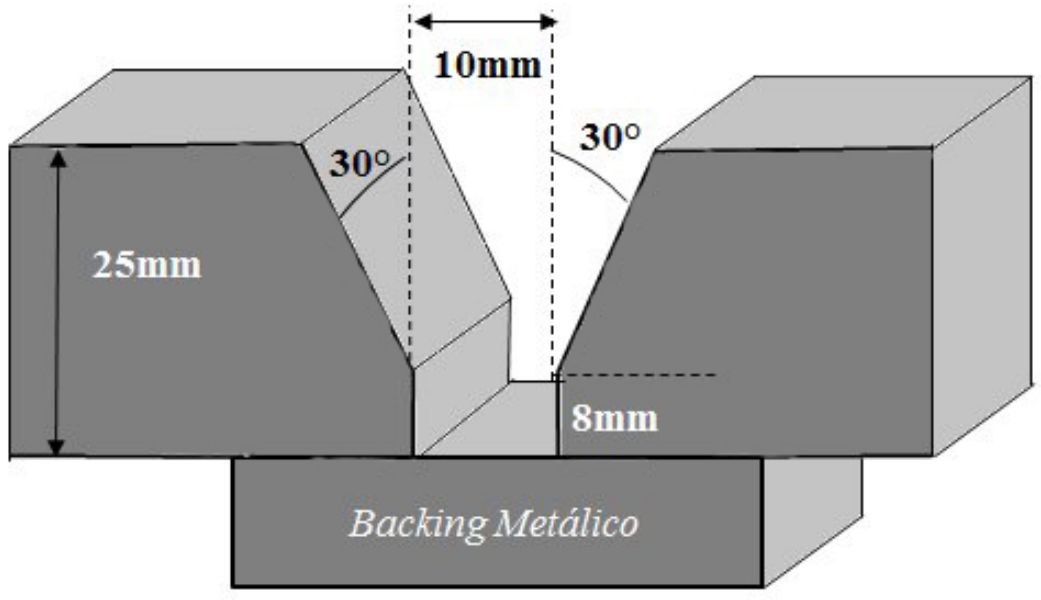

Figura 1. Desenho esquemático com dimensões e formato da junta usada.

Tabela 2. Composição química e propriedades mecânicas do metal depositado indicadas pelo fabricante para os consumíveis usados [19].

\begin{tabular}{ccc}
\hline $\begin{array}{c}\text { Consumíveis } \\
\text { (AWS A5.17) }\end{array}$ & Composição Típica (\%p) & Propriedades Mecânicas Típicas \\
F48A4 - EM12K & $0,05 \% \mathrm{C}-0,24 \% \mathrm{Si}-1,20 \% \mathrm{Mn}-0,10 \% \mathrm{Cu}$ & $\mathrm{LE}=420 ; \mathrm{LR}=500 ; \mathrm{A}=30$ \\
F55A3 - EA2-A4 & $0,05 \% \mathrm{C}-0,40 \% \mathrm{Si}-1,40 \% \mathrm{Mn}-0,50 \% \mathrm{Mo}$ & $\mathrm{LE}=520 ; \mathrm{LR}=590 ; \mathrm{A}=24$ \\
\hline
\end{tabular}

LE - Limite de escoamento (MPa); LR - Limite de resistência (MPa); e A - alongamento (\%).

Foram realizados testes de soldagem com aporte térmico variando entre 2,8 e 17,1 kJ/mm (considerando um rendimento térmico igual a um). As soldas com aporte de 2,8 e 6,9 kJ/mm foram feitas sobre chapa, e as com maior aporte térmico foram feitas no chanfro em "V" mostrado esquematicamente na Figura 1. Para as condições de maior aporte $(6,9,10,7$ e 17,1 kJ/mm), as soldas foram feitas com duas tochas, de acordo com a configuração mostrada na Figura 2: uma tocha ICE ${ }^{\mathrm{TM}}$ com três arames de 2,5 mm, sendo um arame frio e dois energizados por uma única fonte operando com corrente alternada (Twin), e uma tocha guia ligada numa fonte operando com corrente contínua (CC+ Tandem) com arame de 4,0 mm de diâmetro. Para o teste com menor aporte térmico $(2,8 \mathrm{~kJ} / \mathrm{mm})$, usou-se apenas a tocha ICE ${ }^{\mathrm{TM}}$ com a mesma configuração descrita.

Dois testes foram feitos com 17,1 kJ/mm. No primeiro, foi usado, na tocha guia, o arame AWS EM12K e, no segundo, o arame AWS EA2, que possui em sua composição química, adição de Mo e teor de Mn cerca de $10 \%$ maior que o EM12K. Os parâmetros nominais de soldagem e a nomenclatura usada encontram-se na Tabela 3. Em todos os cordões, foi mantido stick-out de $38 \mathrm{~mm}$ e velocidade de alimentação de arame frio no cabeçote ICE ${ }^{\circledR}$ de $40 \%$ dos demais arames. Além disso, após o processo de soldagem, a escória foi mantida por 30 minutos e então removida, seguida de resfriamento ao ar com temperatura ambiente em torno de $29^{\circ} \mathrm{C}$.

A análise das soldas obtidas compreendeu as seguintes etapas: primeiramente foi medida a composição química em amostras da zona fundida de todos os aportes térmicos empregados, por meio de um espectrômetro 


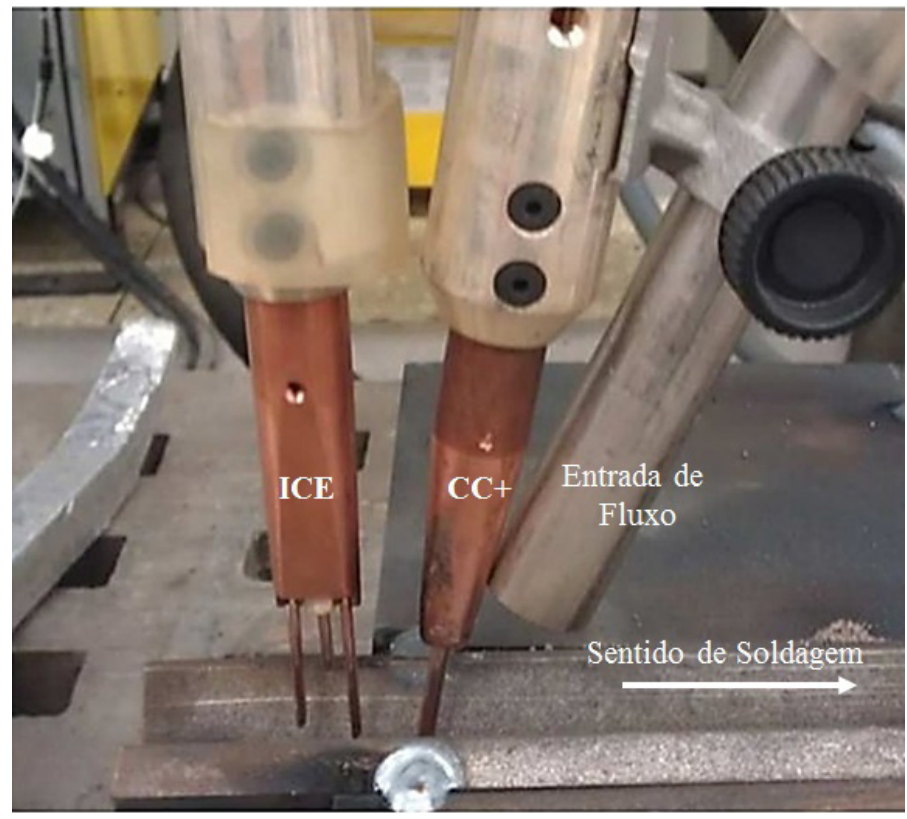

Figura 2. Configuração do equipamento para a realização da soldagem de alto aporte. ICE - Integrated Cold Electrode; CC+ - Corrente Contínua com pólo positivo.

Tabela 3. Parâmetros de soldagem utilizados.

\begin{tabular}{|c|c|c|c|c|c|c|}
\hline Cordão & Tocha & Corrente (A) & Tensão (V) & $\begin{array}{l}\text { Velocidade } \\
\text { (mm/s) }\end{array}$ & $\begin{array}{c}\text { Aporte de Calor } \\
(\mathrm{kJ} / \mathrm{mm})\end{array}$ & Tipo de solda \\
\hline \multirow[t]{2}{*}{ H2.8 } & ICE & 850 & 33 & 10 & 2,8 & Cordão sobre Chapa \\
\hline & $\mathrm{DC}+$ & 0 & 0 & 0 & & \\
\hline \multirow[t]{2}{*}{ H6.9 } & ICE & 850 & 33 & 8,3 & 6,9 & \\
\hline & DC+ & 900 & 33 & 8,3 & & \\
\hline \multirow[t]{2}{*}{ H10.7 } & ICE & 1000 & 35 & 6,7 & 10,7 & Em chanfro (Figura 1) \\
\hline & $\mathrm{DC}+$ & 1000 & 36 & 6,7 & & \\
\hline \multirow[t]{2}{*}{ H17.1 } & ICE & 1000 & 35 & 4,2 & 17,1 & \\
\hline & DC+ & 1000 & 36 & 4,2 & & \\
\hline \multirow[t]{2}{*}{ H17.1 Mo } & ICE & 1000 & 35 & 4,2 & 17,1 & \\
\hline & $\mathrm{DC}+$ & 1000 & 36 & 4,2 & & \\
\hline
\end{tabular}

de emissão óptica. Em seguida, foi realizada a macrografia com lixamento em folhas de carboneto de silício e ataque com reagente Nital $10 \%$. Por fim, foi realizado o preparo para análise micrográfica com lixamento até a granulometria 1200 e polimento em pasta de diamante até $1 \mu \mathrm{m}$ seguido de ataque com Nital 2\%. As estruturas foram analisadas por microscopia óptica e eletrônica de varredura. Foram observadas as características da microestrutura da zona fundida (ZF) e identificados os constituintes microestruturais de acordo com a nomenclatura do International Institute of Welding (IIW) [20,21]. A metalografia quantitativa foi feita pelo método de contagem de pontos, descrito pela Norma ASTM E562 [22].

Além disso, por meio de um durômetro Future Tech modelo FV ARS 9000, foi elaborado com auxílio do software Matlab, um mapeamento de dureza Vickers com carga aplicada de 3 kgf e distância entre pontos de 0,5 mm ao longo da seção transversal do cordão de solda, na mesma região da análise microestrutural como pode ser observado esquematicamente na Figura $3 a$ e b. Por fim, foram realizados ensaios de tração na seção transversal dos cordões de solda feitos em chanfro e também no metal base sentido longitudinal à laminação, segundo a Norma ASTM E8M [23] numa máquina Instron modelo 5582 eletromecânica de 100 kN, também na região central, como mostrado na Figura 3c. Para tal, foram retirados corpos de prova de três regiões distintas no comprimento do cordão de solda para cada variável, obtendo-se um valor médio e o desvio padrão para cada resultado. 


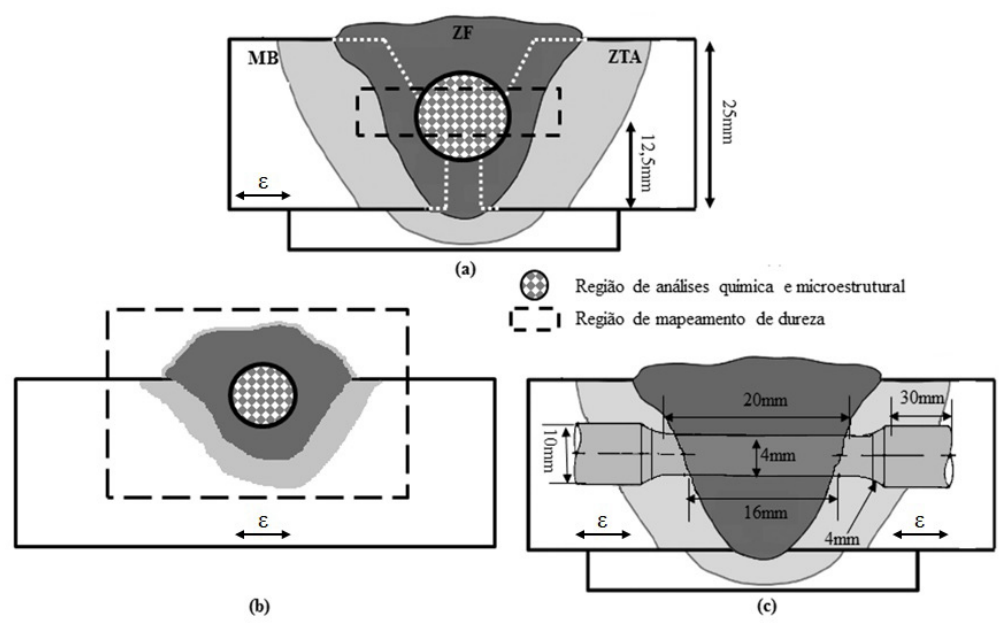

Figura 3. (a) Representação esquemática das regiões de análise dos cordões 3 e 4; (b) representação esquemática das regiões de análise dos cordões 1 e 2; (c) representação esquemática da região de retirada dos corpos de prova de tração com suas respectivas dimensões. $\varepsilon$ - direção de laminação; MB - Metal Base; ZF - Zona Fundida; ZTA - Zona Termicamente Afetada.

\section{Resultados e Discussão}

Na Tabela 4 é mostrada a composição química final dos cordões de solda. Os cordões, de maneira geral, apresentaram uma composição química que condiz com a dos metais de adição empregados, exibindo valores reduzidos de carbono equivalente, o que também contribuiu para a ausência de trincas de solidificação e à frio. O teor de molibdênio, cerca de 10 vezes maior na solda com o arame EA2 em relação aos demais cordões, já era esperado, visto que este arame pode fornecer um metal depositado com teor deste elemento típico de 0,50\%. Considerando a participação dos outros arames no cabeçote ICE, além da diluição do metal base, deve-se esperar um menor teor de Mo, como o encontrado de 0,11\%. A presença deste elemento deve contribuir para aumentar a temperabilidade do aço nesta junta soldada [10].

Tabela 4. Composição química da zona fundida (\%p).

\begin{tabular}{|c|c|c|c|c|c|c|c|c|c|c|c|c|c|c|}
\hline $\begin{array}{l}\text { Aporte } \\
\text { (kJ/mm) }\end{array}$ & C & Mn & Si & $\mathbf{P}$ & $\mathbf{S}$ & $\mathrm{Cr}$ & Mo & $\mathbf{N i}$ & $\mathrm{Cu}$ & V & $\mathbf{N}$ & Ti & $\mathrm{C}_{\mathrm{eq}}$ & $\mathbf{P}_{\mathrm{cm}}$ \\
\hline 2,8 & 0,092 & 1,335 & 0,274 & 0,020 & 0,005 & 0,024 & 0,008 & 0,005 & 0,020 & 0,001 & 0,012 & 0,008 & 0,323 & 0,171 \\
\hline 6,9 & 0,090 & 1,321 & 0,289 & 0,021 & 0,008 & 0,029 & 0,008 & 0,006 & 0,023 & 0,002 & 0,004 & 0,005 & 0,320 & 0,169 \\
\hline 10,7 & 0,084 & 1,360 & 0,230 & 0,012 & 0,006 & 0,020 & 0,010 & 0,009 & 0,010 & 0,003 & --- & 0,010 & 0,319 & 0,162 \\
\hline 17,1 (EM12K) & 0,078 & 1,350 & 0,230 & 0,012 & 0,008 & 0,020 & 0,010 & 0,010 & 0,010 & 0,002 & --- & 0,011 & 0,311 & 0,156 \\
\hline 17,1 (EA2) & 0,084 & 1,250 & 0,270 & 0,015 & 0,005 & 0,060 & 0,120 & 0,020 & 0,070 & 0,002 & 0,008 & 0,004 & 0,335 & 0,171 \\
\hline
\end{tabular}

Destacam-se também os teores reduzidos de fósforo e enxofre, o que minimiza a formação de inclusões não-metálicas de sulfeto de manganês e a segregação do fósforo no contorno de grão austenítico, fatores que afetam negativamente a tenacidade do aço [24]. Inclusões do tipo globular observadas no metal de solda foram predominantemente compostas de óxidos provenientes da reação entre o metal líquido e o fluxo de soldagem utilizado. Essas inclusões contribuíram positivamente atuando como sítios de nucleação de ferrita acicular [25].

As macrografias realizadas neste trabalho são mostradas nas Figuras 4 e 5. Na Figura 4, apresenta-se as macrografias das amostras depositadas sobre chapa. Nessas soldas houve um acréscimo da diluição com o aporte térmico, passando de $42 \%$ na Figura $4 a$ para $62 \%$ na Figura 4b, devido a um aumento mais forte da penetração em relação à quantidade de metal depositado. Este efeito deve estar também associado ao uso do cabeçote líder operando em CC+ para o aporte de $6,9 \mathrm{~kJ} / \mathrm{mm}$. Em processos com eletrodo consumível, o uso de corrente contínua com polaridade positiva tende a favorecer uma maior penetração [26]. 


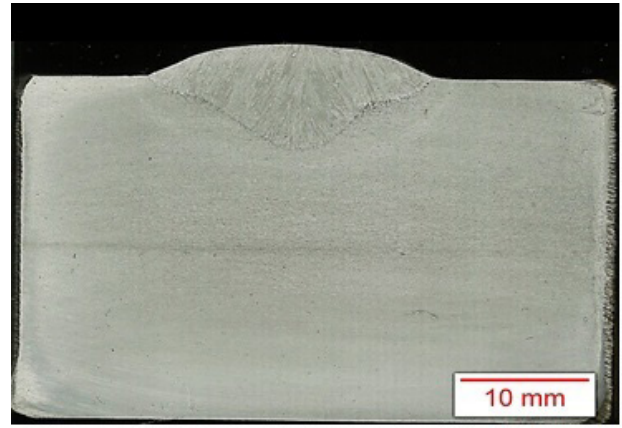

(a)

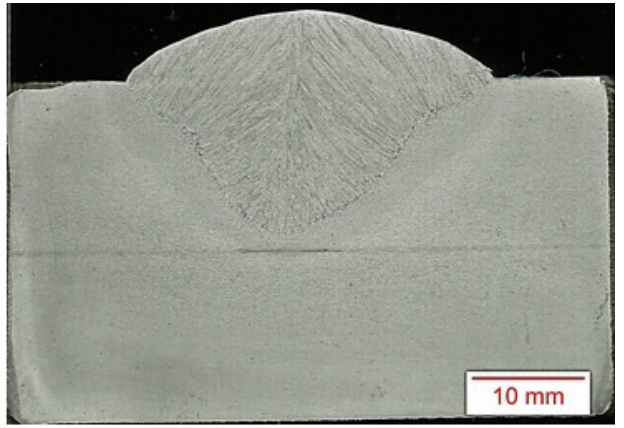

(b)

Figura 4. Macrografias dos cordões depositados sobre chapa: (a) 2,8 kJ/mm; (b) 6,9 kJ/mm. Ataque: Nital $10 \%$.

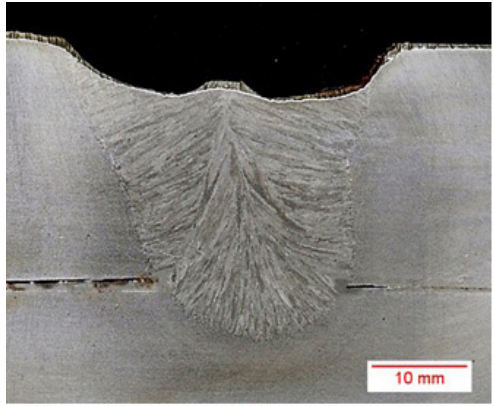

(a)

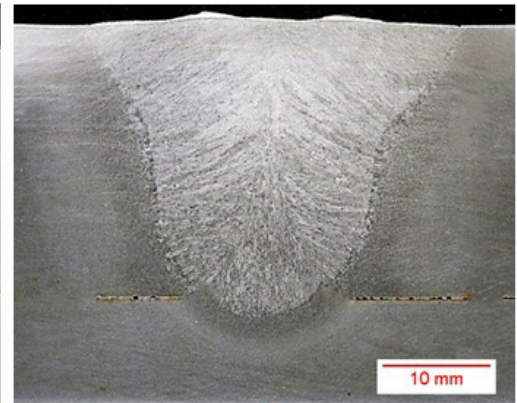

(b)

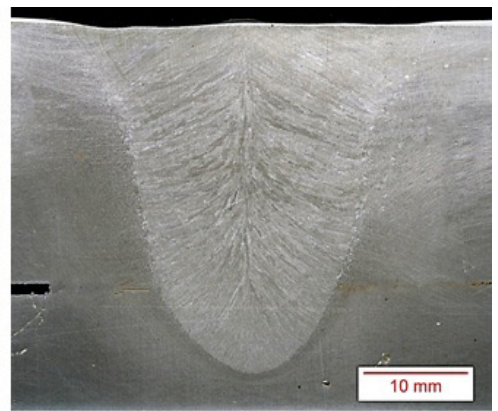

(c)

Figura 5. Macrografias dos cordões depositados em chanfro: (a) 10,7kJ/mm; (b) 17,1kJ/mm; (c) 17,1kJ/mm (EA2). Ataque: Nital $10 \%$

Como pode ser observado na Figura 5a, para o aporte de $10,7 \mathrm{~kJ} / \mathrm{mm}$ não foi possível preencher todo o chanfro, atingindo aproximadamente $2 / 3$ de sua profundidade. Este resultado era esperado, pois o chanfro usado foi planejado para os testes com maior aporte térmico. Assim, optou-se por não depositar um segundo passe de modo a não alterar a microestrutura uma vez que se buscou, neste trabalho, comparar as características da zona fundida não alterada, de apenas um único passe. $O$ uso do aporte de 17,1 kJ/mm (Figura $5 \mathrm{~b}$ e c) proporcionou um preenchimento total e bom acabamento.

A diluição das soldas feitas em chanfro mostradas na Figura 5 foram de $47 \%$ para a condição de $10,7 \mathrm{~kJ} / \mathrm{mm}$, $33 \%$ para a $17,1 \mathrm{~kJ} / \mathrm{mm}$ (EM12K) e de $45 \%$ na solda de $17,1 \mathrm{~kJ} / \mathrm{mm}$ (EA2), sendo menores que aquelas soldas feitas sobre chapa. Este comportamento pode ser esperado considerando que o metal depositado é mais livre para escoar lateralmente na deposição de cordão sobre chapa permitindo uma interação mais direta do(s) arco(s) com o metal base. A variação de diluição não parece afetar de uma forma muito clara a composição da solda. Isto não é surpreendente considerando que se trabalhou deposição de cordão sobre chapa e em chanfro e com diferentes arranjos de cabeçotes e de metais de adição. Além disto, a interação do metal líquido com a escória também tem um papel importante na determinação da composição da solda. Esta interação é afetada por vários detalhes do procedimento de soldagem, particularmente aqueles que afetam a quantidade de fluxo fundido em relação à quantidade de metal de adição, o que não foi avaliado no presente trabalho.

Além disto, considerando as variações relativamente pequenas de composição obtidas, uma análise destes fatores se torna bastante complexa. De uma forma geral, para os testes feitos sem o arame ligado, as tendências observadas foram um aumento dos teores de carbono (12\%), silício (20\%) e fósforo (50\%) nas soldas feitas sobre chapa. Este último, contudo, embora apresente uma variação elevada, manteve-se em teores de até $0,021 \%$ para todas as soldas. Considerando, o uso do arame de baixa liga, foi observado um aumento nos teores de Mo, Cr e Cu e uma redução no teor de Mn (Tabela 4). A variação observada com o Mo é a esperada, enquanto que as demais não eram esperadas, exceto, talvez, a do $\mathrm{Cr}$, que tendo características similares ao Mo, poderia estar também presente no arame. 
Assim, de maneira geral, em todos os cordões, não ocorreram defeitos como falta de fusão, trincamento à frio, trincas de solidificação e porosidade. Além disso, a elevada espessura da chapa proporcionou eficiente dissipação de calor, fazendo com que a ZTA apresentasse uma extensão semelhante àquelas obtidas a partir de aportes térmicos menores [27]. Nota-se que a escolha desta configuração de chanfro mostrou-se adequada para a aplicação na soldagem de alto aporte de chapas de elevada espessura e único passe.

As microestruturas obtidas para cada cordão de solda são mostradas na Figura 6. Qualitativamente, pode-se observar, que tanto os tamanhos de grão austenítico, da ferrita de contorno de grão (GF) e da ferrita intragranular (IF) quanto suas quantidades observadas, aumentam com o acréscimo do aporte térmico. Além disso, a quantidade de ferrita acicular (AF) diminuiu com o aumento do aporte térmico. Este resultado era esperado, pois, com o aumento dos tempos de permanência a alta temperatura e a redução da velocidade de resfriamento resultantes do aumento do aporte térmico, são favorecidos o crescimento de grão, a redução da taxa de nucleação e a presença de constituintes resultantes da decomposição da austenita de temperatura de formação mais alta [25,28]. Estas alterações microestruturais indicam uma possível diminuição de resistência mecânica e de tenacidade do metal de solda. Para aportes até $10,7 \mathrm{~kJ} / \mathrm{mm}$ obteve-se uma microestrutura mais refinada que as de $17,1 \mathrm{~kJ} / \mathrm{mm}$ indicando sua possibilidade de melhores propriedades mecânicas.

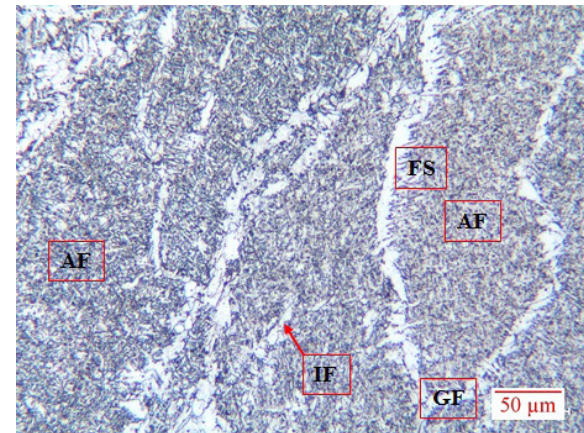

(a)

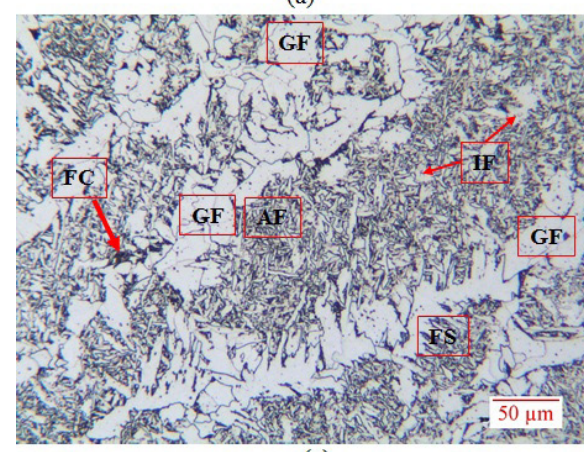

(c)

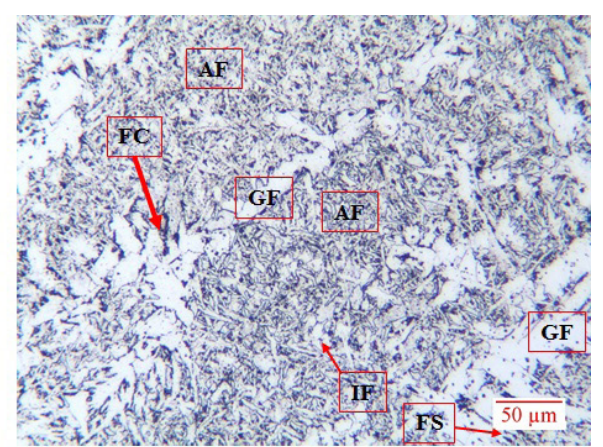

(b)

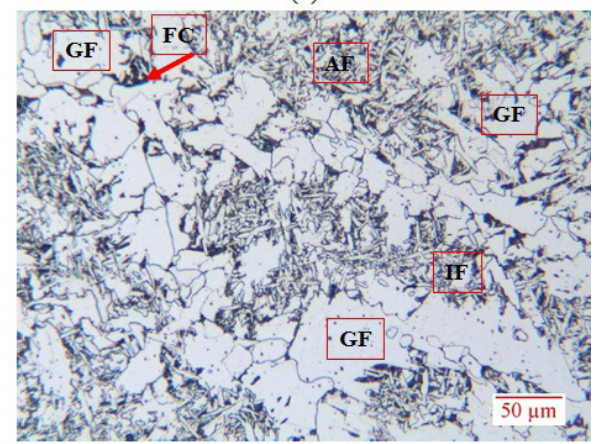

(d)

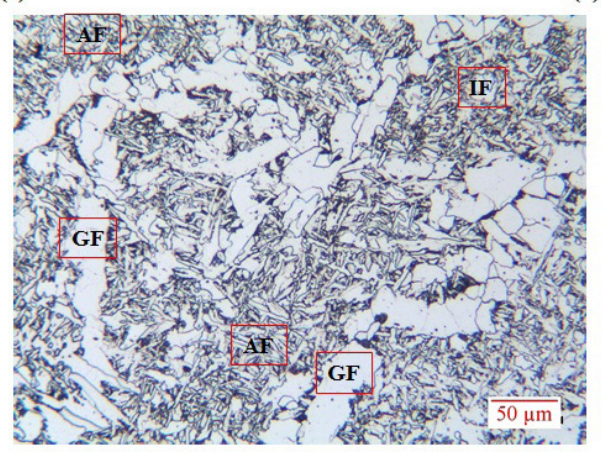

(e)

Figura 6. Evolução da microestrutura com o aumento do aporte térmico: (a) 2,8kJ/mm; (b) 6,9kJ/mm; (c) 10,7kJ/mm; (d) $17,1 \mathrm{~kJ} / \mathrm{mm}$ (EM12K); (e) 17,1 kJ/mm (EA2). AF - Ferrita Acicular; FS - Ferrita com Segunda Fase Alinhada; IF - Ferrita Intragranular; GF - Ferrita de Contorno de Grão; FC - Agregado Ferrita-Carboneto. 
Microestrutura e Características Mecânicas da Zona Fundida de um Aço Naval Soldado ao Arco Submerso com Aporte Térmico Muito Elevado

A Figura 7 mostra os resultados da análise quantitativa da microestrutura para as soldas feitas com o mesmo metal de adição. Estes resultados, de uma forma geral, concordam com a análise qualitativa feita no parágrafo anterior. Com a variação do aporte térmico de 2,8 para 17,1 kJ/mm, a quantidade de ferrita acicular foi reduzida à metade atingindo a fração volumétrica de aproximadamente $30 \%$. Por outro lado, a quantidade de ferrita primária, tanto no contorno de grão austenítico como intragranular, aumentou continuamente, constituindo, na solda com maior aporte térmico, mais de $50 \%$ da microestrutura. Nota-se também a diferença no tamanho das regiões escuras que são associadas à presença de carbonetos e aos constituintes de pequena dimensão como o M-A (Martensita-Austenita). O aumento do aporte térmico proporciona um aumento nas dimensões dessas ilhas de Agregados Ferrita-Carboneto (FC) principalmente junto à GF, que pode estar associado aos maiores tempos de permanência em elevadas temperaturas, facilitando a difusão do carbono para essas regiões [10].

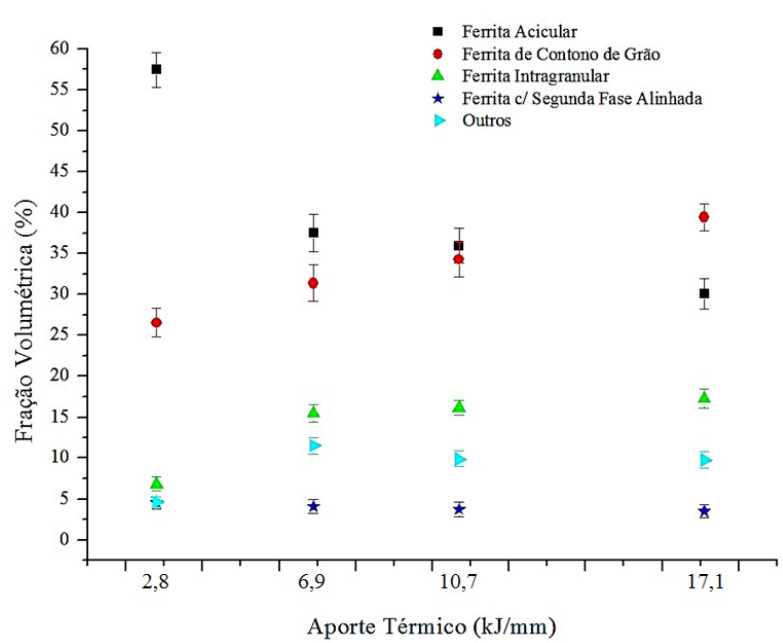

Figura 7. Efeito do aporte térmico na fração volumétrica de constituintes da zona fundida.

Na Figura 8, pode-se comparar o efeito da composição química do arame na microestrutura das soldas feitas com o aporte de $17,1 \mathrm{~kJ} / \mathrm{mm}$. O aumento da temperabilidade conferido principalmente pelo molibdênio permitiu um aumento significativo na quantidade de ferrita acicular com correspondente redução dos outros constituintes, podendo ser interpretada também como o efeito do Mo, que previne a formação de ferrita de contorno de grão levando à maior formação de ferrita acicular [25,28-30].

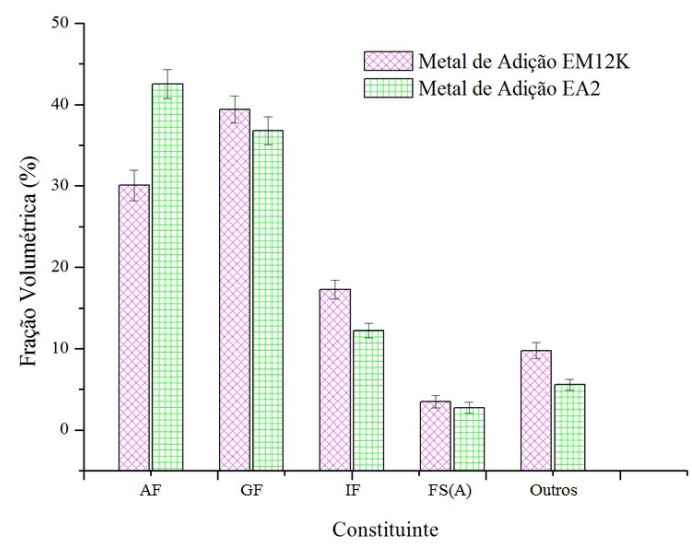

Figura 8. Efeito da composição química do metal de adição na fração volumétrica de constituintes da zona fundida das soldas de 17,1 kJ/mm. AF - Ferrita Acicular; FS(A) - Ferrita com Segunda Fase Alinhada; IF - Ferrita Intragranular; GF - Ferrita de Contorno de Grão. 
Numa análise mais detalhada, realizada nas amostras soldadas em chanfro e mostrada na Figura 9, pode-se detectar a presença de bainita (B), perlita $\mathrm{FC}(\mathrm{P})$ e constituinte $\mathrm{M}-\mathrm{A}$ distribuído ao longo de toda a imagem, mas podendo ser encontrado com mais facilidade entre as placas da ferrita acicular e ao longo dos contornos de grão da GF. A presença do M-A é indesejável pois trata-se de um constituinte de elevada fragilidade o qual prejudica as propriedades mecânicas da junta soldada. Contudo, com o aumento do aporte térmico na soldagem, a fração volumétrica do constituinte $\mathrm{M}-\mathrm{A}$ tende a diminuir devido ao aumento do ciclo térmico e redução na taxa de resfriamento, o que possibilita sua decomposição em ferrita e carbonetos [11].
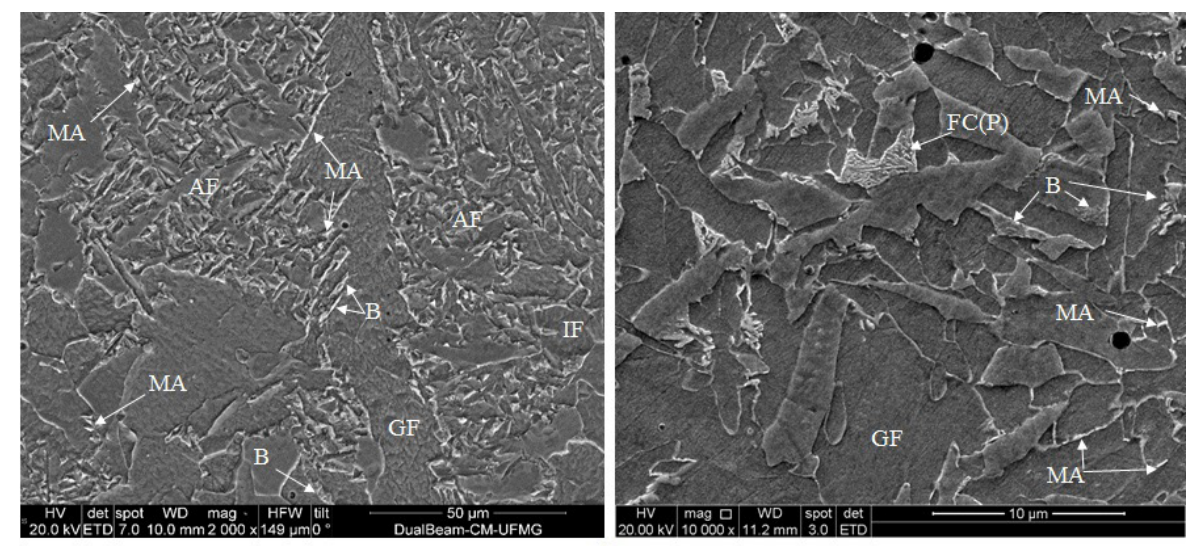

(a)
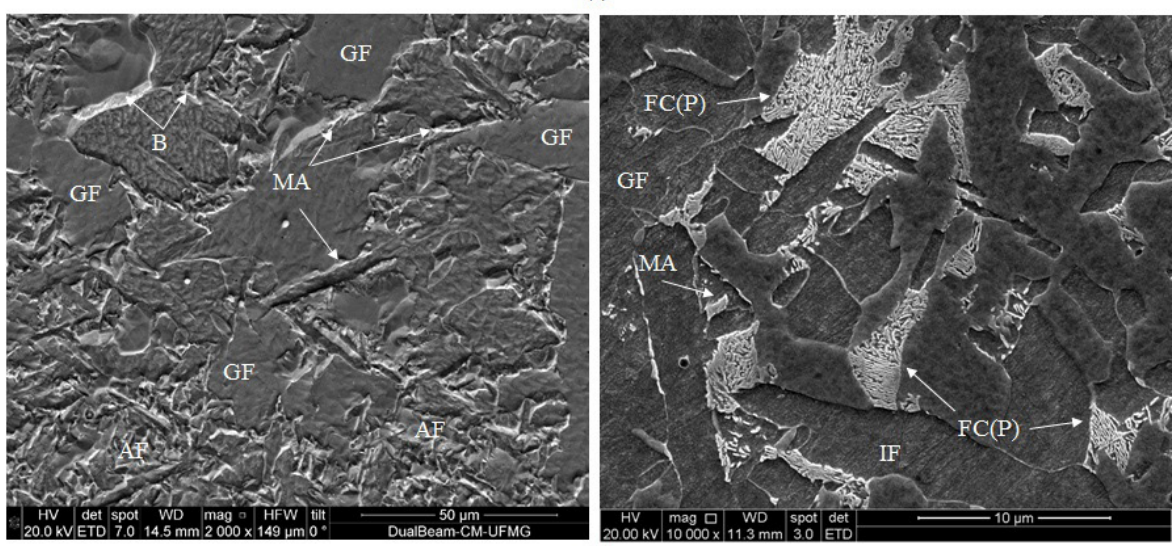

(b)
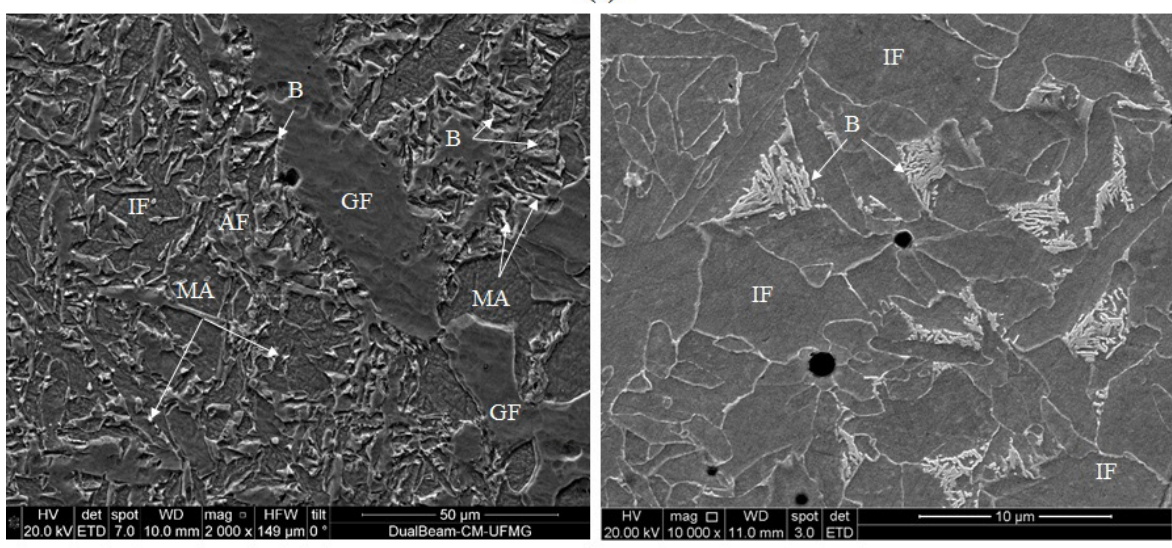

(c)

Figura 9. Análise complementar no microscópio eletrônico de varredura. Detalhe das regiões de constituinte MA perlita (FC(P)) e bainita (B); (a) 10,7 kJ/mm; (b) 17,1 kJ/mm (EM12K); (c) 17,1 kJ/mm (EA2). MA - Constituinte Martensita/Austenita; AF - Ferrita Acicular; B - Bainita; FC(P) - Perlita; IF - Ferrita Intragranular; GF - Ferrita de Contorno de Grão. 
Microestrutura e Características Mecânicas da Zona Fundida de um Aço Naval Soldado ao Arco Submerso com Aporte Térmico Muito Elevado

Os resultados dos testes de tração para o metal base e os cordões soldados em chanfro com $10,7 \mathrm{~kJ} / \mathrm{mm} \mathrm{e}$ $17,1 \mathrm{~kJ} / \mathrm{mm}$ encontram-se na Tabela 5 . Em todos os corpos de prova da junta soldada, as fraturas ocorreram no metal de solda, tendo sido usinados com o comprimento útil abrangendo essa região, como mostrado na Figura 3c. Todos eles se romperam com fratura essencialmente dúctil, observando-se, com o microscópio eletrônico de varredura, a presença típica de microcavidades nestas superfícies.

Tabela 5. Propriedades mecânicas básicas da zona fundida e metal base.

\begin{tabular}{cccccc}
\hline Aporte $(\mathbf{k J} / \mathbf{m m})$ & LE (MPa) & LR (MPa) & Alongamento \% & RE (\%) & $\overline{\boldsymbol{H V}} 3$ \\
$\mathbf{1 0 , 7}$ & $424 \pm 2$ & $542 \pm 15$ & $21 \pm 2$ & 78 & $176 \pm 5$ \\
$\mathbf{1 7 , 1}$ EM12K & $342 \pm 16$ & $496 \pm 16$ & $25 \pm 1$ & 69 & $154 \pm 4$ \\
$\mathbf{1 7 , 1}$ EA2 & $422 \pm 8$ & $558 \pm 10$ & $18 \pm 1$ & 76 & $184 \pm 6$ \\
Metal Base & $375 \pm 3$ & $490 \pm 8$ & $29 \pm 1$ & 77 & $160 \pm 5$ \\
\hline
\end{tabular}

LE - Limite de Escoamento; LR - Limite de Resistência; RE - Razão Elástica; $\overline{H V}$ - Dureza Vickers média.

Os valores encontrados para o metal base estão dentro da faixa aceita pela Norma ASTM A131M [18]. Pode-se observar que as condições de soldagem que proporcionaram maior fração volumétrica de ferrita acicular, apresentaram maior limite de escoamento, resistência e dureza. Já a condição de maior aporte que apresentou majoritariamente a ferrita primária com granulação grosseira, mostrou-se com os menores valores de propriedades mecânicas e alongamento. Destaca-se nessa comparação, o metal de solda com adição de Mo, que apresentou a maior resistência mecânica mesmo quando comparado com os resultados da solda feita com menor energia, demostrando o bom comportamento deste arame para as condições de soldagem aplicadas. Este resultado também pode ser atribuído ao aumento da temperabilidade do metal de solda pelo Mo o que pode ter contrabalanceado as menores velocidades de resfriamento associadas com a aumento do aporte térmico [29,30].

Nas Figuras 10 e 11 são mostrados os mapas de dureza obtidos na seção transversal dos cordões de solda. De maneira geral, como esperado [5,8,11,12,15], a dureza Vickers da zona fundida reduziu com o aumento do aporte térmico. Isso está relacionado principalmente ao aumento do tamanho de grão e à variação dos constituintes microestruturais, consequência dos maiores tempos de permanência em elevadas temperaturas [25,28]. O valor médio de dureza (HV3) da zona fundida para o aporte de $2,8 \mathrm{~kJ} / \mathrm{mm}$ foi de $(202,04 \pm 6,52)$ e para o aporte de $6,9 \mathrm{~kJ} / \mathrm{mm}$ de $(170,33 \pm 3,83)$. O cordão de 10,7 kJ/mm (Figura 11a), apresentou dureza superior ao cordão de $6,9 \mathrm{~kJ} / \mathrm{mm}$ (Figura 10b), feito sobre chapa. Nesse caso, o principal motivo pode estar relacionado, às taxas de resfriamento em cada situação, uma vez que escoamento de calor do metal depositado em chanfro tende a ser melhor que aqueles depositados sobre chapa, pois existe uma maior superfície de contato com as paredes do chanfro e com o backing, o que facilita e acelera a condução térmica para a peça [27].

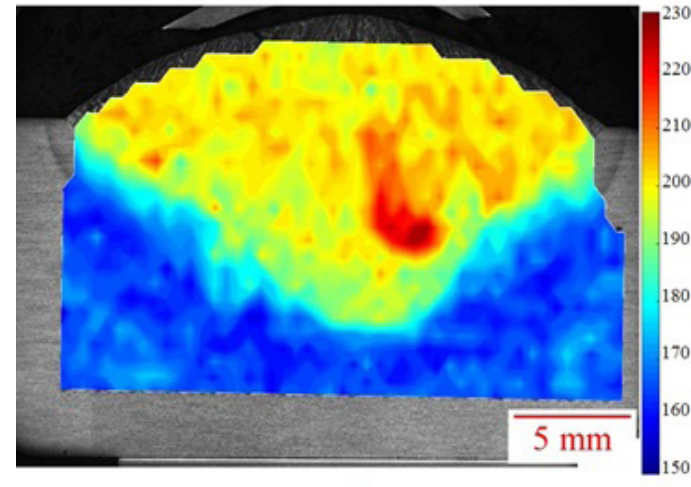

(a)

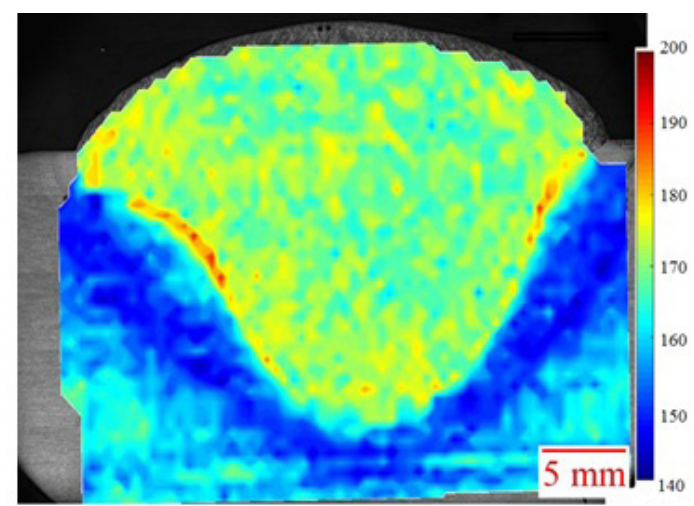

(b)

Figura 10. Mapeamento de dureza na seção transversal dos cordões depositados sobre chapa: (a) 2,8 kJ/mm; (b) $6.9 \mathrm{~kJ} / \mathrm{mm}$. 

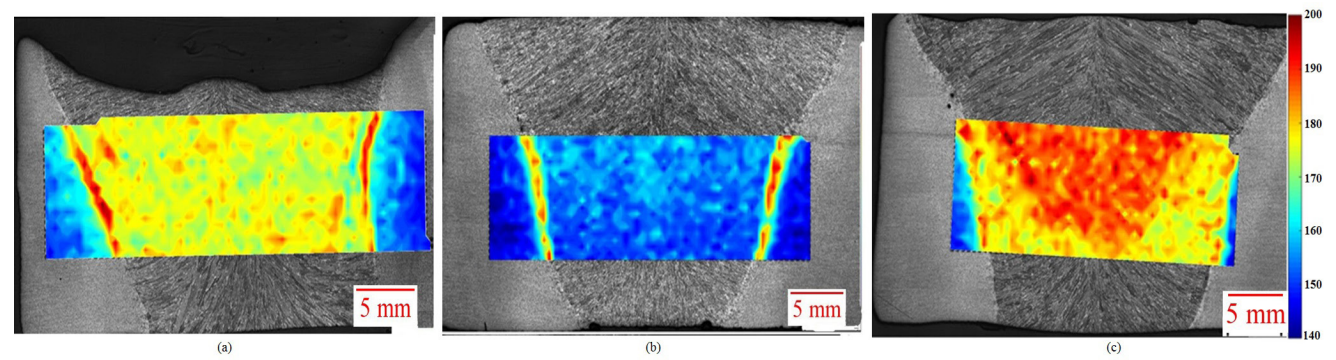

Figura 11. Mapeamento de dureza na seção transversal dos cordões depositados em chanfro: (a) 10,6 kJ/mm; (b) $17,1 \mathrm{~kJ} / \mathrm{mm}$ (EM12K); (c) $17.1 \mathrm{~kJ} / \mathrm{mm}$ (EA2).

A variação de dureza mais notável está entre os cordões de 10,6 kJ/mm e o de 17,1 kJ/mm (EM12K) (Figura 11a e b respectivamente), bem como entre este último e o de $17,1 \mathrm{~kJ} / \mathrm{mm}$ (EA2) (Figura $11 \mathrm{~b}$ e c respectivamente). No primeiro caso, fica clara a influência do aporte térmico na microestrutura já que os consumíveis utilizados foram os mesmos. Esta variação de aporte proporcionou a formação de grãos grosseiros de ferrita de contorno de grão e intragranular, que conferem ao material baixa resistência mecânica, situação já evidenciada na Tabela 5 . A segunda situação mostra a influência dos consumíveis utilizados, já que foram mantidos os parâmetros de soldagem e condições de resfriamento. Nesse caso, a adição de um arame contendo molibdênio contribuiu também para o aumento da dureza nesse cordão, devido à uma microestrutura com menor tamanho de grão da ferrita primária e com maior presença de ferrita acicular, constituintes que proporcionam elevada resistência mecânica, como foi observado na Figura 6 e também nos resultados de ensaios de tração.

A zona termicamente afetada não foi abrangida completamente por este mapeamento de dureza, mas é possível perceber em partes, regiões com os menores valores de dureza medidos nas extremidades do mapeamento, sendo associada ao amaciamento da ZTA. Este fenômeno é relatado como comum para este tipo de aço, observado por Silva et al. [31] e Borba et al. [15], e está relacionado ao seu baixo carbono equivalente. Já na linha de fusão, há um aumento localizado da dureza, numa área que coincide com a região de grãos grosseiros da ZTA.

\section{Conclusões}

Neste trabalho, a influência do aporte térmico na microestrutura de soldas de único passe foi avaliada, bem como a sua consequência nas propriedades de tração e dureza da zona fundida com os consumíveis utilizados. A partir dos resultados mostrados, pode-se concluir que:

- Na soldagem ao arco submerso em único passe usando-se o arame AWS EM12K se obtém uma microestrutura refinada, composta principalmente por ferrita acicular e proporciona boas propriedades mecânicas para aportes até $10,7 \mathrm{~kJ} / \mathrm{mm}$;

- Para valores de aporte superiores a este, haverá degradação dessas propriedades na zona fundida devido à formação de estruturas grosseiras tais como ferrita de contorno de grão e ferrita intragranular;

- Alterações pouco significativas na composição química entre as amostras soldadas com os mesmos consumíveis implicam na eventual ausência do efeito da diluição nessas propriedades mecânicas;

- Já para condições de aporte térmico de $17,1 \mathrm{~kJ} / \mathrm{mm}$, o uso de arame com adição de molibdênio, no caso o AWS EA2, em conjunto com o AWS EM12K e fluxo OK Flux 10.71 conferiu boas propriedades de dureza e tração devido ao aumento da temperabilidade e fração volumétrica de ferrita acicular. Assim, para estas condições de soldagem, tal combinação de consumíveis se mostrou adequada.

\section{Agradecimentos}

Os autores agradecem a todos que contribuíram para a realização deste trabalho, em especial, à ESAB, na pessoa do Dr. Ronaldo Cardoso Júnior pelo o apoio fundamental no fornecimento de consumíveis e confecção dos corpos de prova soldados, à Usiminas, pelo fornecimento do metal base e realização das análises de dureza, ao Laboratório de Robótica Soldagem e Simulação pela disponibilidade e à CAPES pelo apoio financeiro. 
Microestrutura e Características Mecânicas da Zona Fundida de um Aço Naval Soldado ao Arco Submerso com Aporte Térmico Muito Elevado

\section{Referências}

[1] Lan L, Kong X, Qiu C, Zhao D, Influence of microstructural aspects on impact toughness of multi-pass submerged arc welded HSLA steel joints. Materials \& Design. 2016;90:488498. http://dx.doi.org/10.1016/j.matdes.2015.10.158.

[2] Kiran D, Alam S, De A. Development of process maps in two-wire tandem submerged arc welding process of HSLA steel. Journal of Materials Engineering and Performance. 2013;22(4):988-994. http://dx.doi.org/10.1007/s11665-012-0381-2.

[3] Tušek J. Metal-powder twin-wire submerged-arc welding. Welding \& Metal Fabrication. 1998;66(7):21-24.

[4] Ramakrishnan M, Padmanaban K. Twin wire with metal powder addition technique in submerged arc welding. In: Proceedings of the International Welding Conference (IWC): Advances in Welding \& Cutting Technology; 2001 Feb 15-17; Lodi Road, New Delhi, India. India: Welding Research Institute; 2001. p. 481-491.

[5] Viano DM, Ahmed NU, Schumann GO. Influence of heat input and travel speed on microstructure and mechanical properties of double tandem submerged arc high strength low alloy steel weldments. Science and Technology of Welding and Joining. 2000;5(1):26-34. http://dx.doi.org/10.1179/stw.2000.5.1.26.

[6] Anderson $O$, Thanlow $C$. The influence of cold wire and fluoride addition on weld metal toughness in submerged arc welding. Weld Metal Fabrication. 1975;43(9):704-708.

[7] Ramakrishnan M, Muthupandi V. Application of submerged arc welding technology with cold wire addition for drum shell long seam butt welds of pressure vessel components. International Journal of Advanced Manufacturing Technology. 2013;65(58):945-956. http://dx.doi.org/10.1007/s00170-012-4230-0.

[8] Mohammadijoo M. Development of a welding process to improve welded microalloyed steel characteristics [PhD thesis]. Canada: Department of Chemical and Materials Engineering, University of Alberta; 2017

[9] ESAB. Welding equipment $A B$, integrated cold electrod submerged arc welding process description. Gothenburg: $E S A B$; 2012 [acesso em 10 mar. 2017]. Disponível em: https://www. esabna.com/us/en/index.cfm

[10] Evans GM, Bailey N. Metallurgy of basic weld metal. New York: Abington Publishing; 1997. http://dx.doi.org/10.1533/9781845698850.

[11] Jorge JCF, Souza LFG, Marouco ES, Santos OR Fo, Diniz JLC. Propriedades mecânicas e microestruturais de juntas soldadas pelo processo a arco submerso com elevado aporte térmico. Soldagem e Inspeção. 2015;20(3):347-358. http://dx.doi. org/10.1590/0104-9224/SI2004.04.

[12] Marouço EDS, Diniz JLC, Santos OR Fo, Souza LFG, Jorge JCF. Estudo do aporte térmico nas propriedades mecânicas de metais de solda de aço c-mn obtidos pelo processo arco submerso. Tecnologica em Metalurgia, Materiais e Mineração. 2013;10(2):128-137. http://dx.doi.org/10.4322/tmm.2013.018.

[13] Gery D, Long H, Maropoulos P. Effects of welding speed, energy input and heat source distribution on temperature variations in butt joint welding. Journal of Materials Processing Technology. 2005;167(2-3):393-401. http://dx.doi.org/10.1016/j. jmatprotec.2005.06.018.

[14] Meester BD. The weldability of modern structural TMCP steels. ISIJ International. 1997;37(6):537-551. http://dx.doi.org/10.2355/ isijinternational.37.537.

[15] Borba TMD, Flores WD, Turani LO, Cardoso R Jr, Avaliação da soldabilidade do aço Naval EH36 TMCP soldado por arco submerso com elevado aporte de calor. Soldagem e Inspeção. 2015;20(1):92-104. http://dx.doi.org/10.1590/0104-9224/ SI2001.10.

[16] Zhao MC, Yang K, Shan Y. The effects of thermo-mechanical control process on microstructures and mechanical properties of a commercial pipeline steel. Materials Science and Engineering. 2002;335(1-2):14-20. http://dx.doi.org/10.1016/ S0921-5093(01)01904-9.

[17] Uemori R. Bulletin of The Iron and Steel Institute of Japan. ISIJ International. 2009;14:34.

[18] American Society for Testing and Materials. ASTM 131/131M: standard specification for structural steel for ships. West Conshohocken: ASTM; 2014.

[19] ESAB. Catálogo de consumíveis. Contagem: ESAB; 2017.

[20] International Institute of Welding. Guide to the light microscope examination of ferritic steel weld metals. France: IIW; 1988. (IIW Doc; IX-1533-88).

[21] Thewlis G. Classification and quantification of microstructures in steels. Materials Science and Technology. 2004;20(2):143 160. http://dx.doi.org/10.1179/026708304225010325.

[22] American Society for Testing and Materials. ASTM E562-11: standard test method for determining volume fraction by systematic manual point count. West Conshohocken: ASTM; 2011.

[23] American Society for Testing and Materials. ASTM E8/E8M-16a: standard test methods for tension testing of metallic materials. West Conshohocken: ASTM; 2016.

[24] Krauss G. Steels: processing, structure and performance. 3rd ed. Materials Park: ASM International; 2005.

[25] Babu SS. The mechanism of acicular ferrite in weld deposits. Current Opinion in Solid State and Materials Science. 2004;8(34):267-278. http://dx.doi.org/10.1016/j.cossms.2004.10.001.

[26] Weman K. Welding processes handbook. 2nd ed. Philadelphia: Woodhead Publishing; 2012.

[27] Gery D, Long H, Maropoulos P. Effects of welding speed, energy input and heat source distribution on temperature variations in butt joint welding. Journal of Materials Processing Technology. 2005;167(2-3):393-401. http://dx.doi.org/10.1016/j. jmatprotec.2005.06.018.

[28] Popovic O, Lukic U, Prokic-Cvetkovic R, Burzic M, Jovicic R. The effect of heat input on the content of acicular ferrite in weld metal of microalloyed steel. In: Proceedings of the 18th International Research/Expert Conference "Trends in the Development of Machinery Ans Associated Technology"; 2014; Budapest, Hungary. Budapest: TMM; 2014; p. 61-64.

[29] Keehan E, Karlsson L, Andrén H-O. Influence of carbon, manganese and nickel on microstructure and properties of strong steel weld metals: parts 1 to 3 . Science and Technology of Welding and Joining. 2006;11(1):1-8. http://dx.doi.org/10.1179/174329306X77830.

[30] Bhole SD, Nemade JB, Collins L, Liu C. Effect of nickel and molybdenum additions on weld metal toughness in a submerged arc welded HSLA line-pipe steel. Journal of Materials Processing Technology. 2006;173(1):92-100. http://dx.doi.org/10.1016/j. jmatprotec.2005.10.028.

[31] Silva RF, Alé RM, Modenesi PJ. Caracterização da zona termicamente afetada de aço produzido via resfriamento acelerado. In: Anais do XXXVI Congresso Nacional de Soldagem (CONSOLDA); 2010; Recife. São Paulo: Associação Brasileira de Soldagem; 2010. p. 1-12. 